\title{
Washington shake-up
}

The magnitude 5.8 earthquake that shook the US east coast in 2011 was a real rattler, triggering landslides over an area 20 times larger than previously seen for a quake of that size.

The far-reaching power of this earthquake has some scientists concerned that seismic risks in the eastern seaboard might be greater than previously thought, potentially requiring a reassessment of building codes and hazard maps.

The 23 August 2011 Virginia earthquake was surprising both for its size and its impact. It was the largest to hit the eastern US since 1897, and it was felt more than $1,600 \mathrm{~km}$ from its epicentre, from Canada to Florida. The shaking did damage to landmark buildings in the US capital: statues toppled from the National Cathedral, and the obelisk-shaped Washington Monument rang like a tuning fork, resulting in cracks on its pyramid top.

To chart the extent of the quake's effects, Randall Jibson, a geologist at the US Geological Survey (USGS) in Denver, and colleague Edwin Harp sought out evidence of small landslides caused by the trembling.

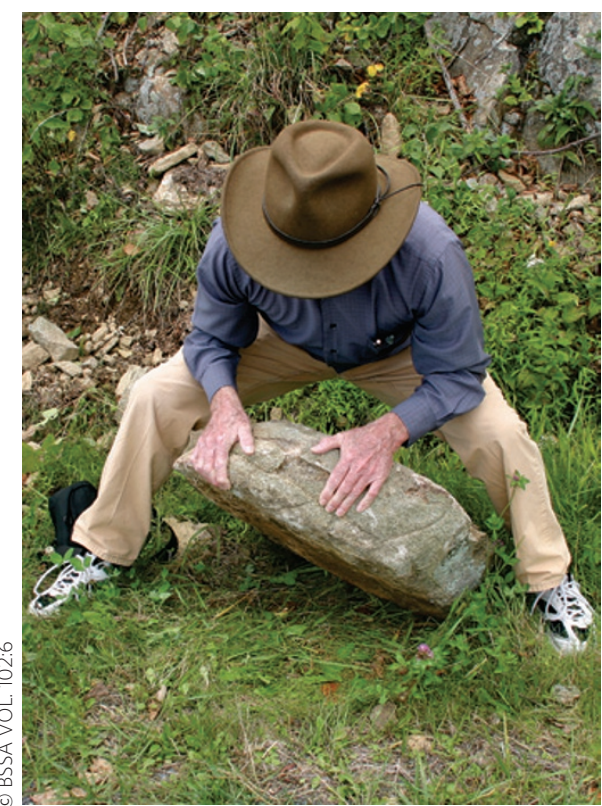

They drove thousands of kilometres over ten days, stopping to pick up fallen boulders and pebbles to see if the stones had moved recently enough to still have green grass underneath. The team found evidence for fresh slides over an oblong area up to $245 \mathrm{~km}$ in radius, beating hands-down the previous record of about $60 \mathrm{~km}$ for a magnitude 5.8 quake (Bull. Seismol. Soc. Am. 102, 2368-2377; 2012). The effects were furthestfelt along the northeast-southwest axis - in the direction of Washington DC and other populated centres.

Mid-continent earthquakes are expected to travel further, and cause more shaking for their magnitude, than quakes at plate boundaries. This is because the crust is harder, denser, colder and less fractured, allowing seismic waves to travel through the ground more easily. Even so, the amount of shaking for this Virginia quake was higher than predicted by models. Jibson estimates that a magnitude 5.8 earthquake in the midtectonic-plate eastern US has about the same impact as a 6.5 that's on the plate boundary in the west.

Nicola Jones is a freelance journalist based in Pemberton, British Columbia, Canada.

\section{The journalist's take}

The eyes of all news editors were fixed firmly on Washington DC in November 2012 for the presidential race. This undoubtedly helped to pique interest in a coincident report about earthquake hazards in the American capital; coverage by Nature made the election link explicit with the punning headline, 'Virginia earthquake wins by a landslide.' Although the paper was not due to be published in the Bulletin of the Seismological Society of America (BSSA) until December, the authors reported their results on 6 November at the annual meeting of the Geological Society of America, prompting both the US Geological Survey and the BSSA to put out press releases pegged to the earlier date. Jibson and Harp did dozens of interviews with journalists, and stories appeared in more than 300 media outlets.

The study contained the one thing every journalist loves most - a record-breaker. At first glance, the superlative here is clear: this earthquake caused the furthestreaching landslides for its size. On closer inspection, that comes with two caveats. First, many quakes, the press release acknowledges, simply aren't investigated enough to see just how far away they rattled small rocks. So this record-breaker could stand out in part because of a lack of previous data. Secondly, it was obvious immediately after the 2011 quake that it had shaken further-reaching sites more thoroughly than expected, both from seismic logs and people's reports of damage. The media ran with stories about that at the time, so a record extent of landslides, on top of the previously reported heavy shaking, may not seem quite so noteworthy.

Regarding the first caveat, the paper itself offers journalists a reason not to worry too much about the potential blow to newsworthiness: "Even taking differential landslide reporting into account, the landslide limits from the 2011 Virginia earthquake are extraordinary," the authors write. Words like "extraordinary" (along with "surprising" and "unusual") are catnip to reporters, especially when they survive the filter of peer review. I have sometimes trawled through the thousands of abstracts in the American Geophysical Union Fall Meeting database by searching for just those words.
The more important question arises from the second caveat: does this study really change what we know about earthquake hazards on the east coast? An argument can be made that Jibson and Harp's landslide data are more objective than people's reports of shaking, and more detailed than the records from sparse seismic stations in the area. But although that counts as a clear step forward within the scientific community, it won't sound like a big deal to a news editor: the conclusions for policymakers remain much the same.

So why did the story get so much play? The caveats are trumped, on balance, by the easy headline that can be written for a record-breaker, along with the fun details about how this study was done. Studies of satellite images may sound very sophisticated, but there's something appealing about a methodology so simple that it could have been a winning entry at a high-school science-fair. Most of all, it's exciting to revisit an event that shook up the country's capital a year ago, and arguably important to remind policymakers about the potential for future harm. 